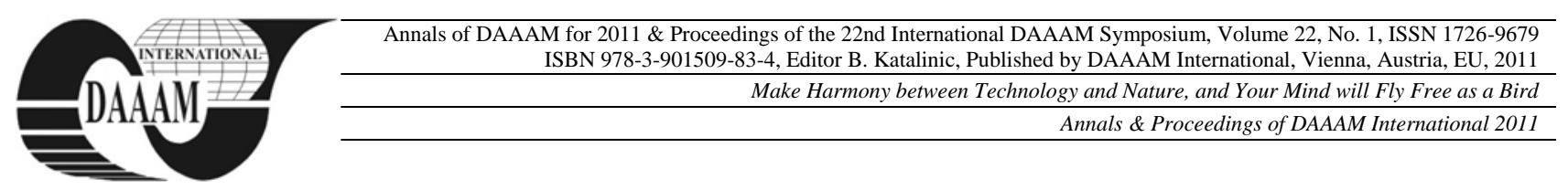

\title{
THE TEAMWORK ABILITIES VERSUS LEADERSHIP
}

\author{
HARANGUS, D[aniela] \& DUDA - DAIANU, D[ana] C[odruta]
}

\begin{abstract}
The issue of the leader development includes the necessity to concurrently form the skills of tem working. The working paper underlines that these two formative desiderate are compatible, correlative and complementary. So, in the study that we undertake we proposed to determine the degree of compatibility between the two demands of education, as follows: the training of leader capable to exercise also the specific activities of teamwork
\end{abstract}

Key words: leadership, teamwork, training, abilities, management potential scale

\section{INTRODUCTION}

The issue of the leader development includes the necessity to concurrently form the skills of team working. Ours main objectives following in this working paper is to demonstrate by our research that these two formative desiderate are compatible, correlative and complementary.

Studies have failed to move beyond the simplistic approaches of the early theories of personality traits; they found that there are certain characteristics that require systematic, and distinguished the leaders by the non-leaders. Most leaders have good skill sets in the following areas: personnel (motivation to succeed, self-confidence, dynamism and personal efficacy), social (ability to influence political discernment, empathy), cognitive (conceptual thinking) and some important skills effectiveness of the leader, closely linked to personality traits: impetuosity, sociability, sensitivity, agreeability, conscientiousness, analytical intelligence, emotional intelligence. Looking at different models of leadership we see that in this increasingly globalize world, begin to crystallize several converging trends that the leaders would be useful: charisma, aptitude for teamwork, openness to change, interest in life public, etc.

There are a number of theories (among these are: major human theory, the theory of specific driver characteristics, driving styles theory, situational theory, etc.) that emphasizes what qualities should an effective leader, which are native and which are acquired, which can be formed or not. It requires more than the view that what matters most is the selection process itself. When choosing careers, for the most part, the training leader has already taken place, in large part, his personality is crystallized. Therefore an organization that is looking for people with "high potential" (often referred to as future leaders) would do well to begin by choosing the right people, not their training to go directly to the appropriate people.

Even if the most good indicator of lead capacity (and the most prediction, in the same time, regarding the potential to lead) was the list of candidates' results and achievements what is called ,track record“, when it taking about a long process, for training the leaders, became useful the studies realized by applying tests to assess their potential.

From the perspective of becoming, a leader is a special way of being, ways that can be learn into cumulative way. It's a kind of being which is acquired every day through the description exercise of the objective reality that must be corrected through specific measures and actions in view to generate performance.

Leader qualities must necessarily include its ability to work together, to be folded on the processes that describe functional and structural developments in embedded team. It is a truism that an individual will never be able to lead if, perhaps, was never be lead wasn't taught to follow the others.

\section{METHODOLOGY OF THE RESEARCH}

Working hypothesis - the high potential of leader is compatible with the requirement for training of teamwork skills.

Population's sample - given that the target population (students) is relatively homogeneous, with management potential measured at higher levels, we opted for the study on a group of 10 subjects, randomly selected.

For checking the hypothesis were following few steps: determining leadership potential, identify characteristics of team behavior, interpretation of results.

A). To determine the potential leader we used California Psychological Inventory (CPI), designed and tested by Harrison G. Gough, one of the most popular tools for investigating personality. Although it was assured the full recovery of the facilities offered by the CPI, in this context emphasize the Managerial Potential Scale (Mp) whose relevance is highlighted by the following interpretation:

- High Scores: indicates individuals who make a good impression and are reliable, fluent in speech, social efficiency, emotionally stable, mature, clear thinking, realistic, optimistic, responsible, capable, well organized and ambitious, are oriented towards objectives, have initiatives and make valuable predictions are an effective leader and able to get cooperation from others, know how to complete activities, offer advice and have a great potential intellectual and cognitive;

- Low scores: individuals are characterized as lacking selfconfidence, socially awkward, which made many mistakes in expression, are emotionally unstable, moody, cantankerous and anxiety, tend to be dissatisfied, rebellious, defensive, immature, apathetic, irresponsible , careless and inconsistent in pursuing long-term objectives, tend to behave as confined in a rut and became anxious to change and retreating in the face of adverse conditions.

$B)$. To identify the characteristics of team behavior we used:

a) an questionnaire comprising 28 items, developed to ensure identification of the following seven dimensions: assertiveness $\left(\mathrm{I}_{1}-\mathrm{I}_{5}\right)$, mission analysis ( $\left.\mathrm{I}_{6}-\mathrm{I}_{9}\right)$, communication $\left(\mathrm{I}_{10}-\mathrm{I}_{14}\right)$, decision ( $\mathrm{I}_{15}-\mathrm{I}_{17}$ ), adaptability ( $\mathrm{I}_{18}-\mathrm{I}_{20}$ ), situational awareness

$\left(\mathrm{I}_{21}-\mathrm{I}_{23}\right)$ leadership $\left(\mathrm{I}_{24}-\mathrm{I}_{28}\right)$.

b) an interview guide focused on the following dimensions: organizational capacity, accountability in decision-making capacity and competence in communication, ability to adapt to changes and self-evaluation capacity. 


\section{RESULTS OF THE RESEARCH}

Interpretation of data and correlations made between the results obtained lead us to validate the hypothesis formulated at the beginning of the study: the high level of leadership potential is compatible with the requirement of teamwork skills training. Compatibility of the two goals is a requirement of doctrinal nature, to which are devoted significant resources of time.

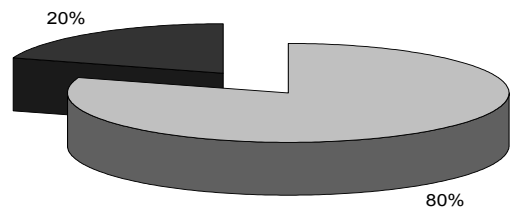

$\square 40-60 \square>60$

Fig. 1. Statistical analysis of the results on the scale of "Management Potential"

Statistical analysis of the results on the scale of "Management Potential" (Figure 1) reveals the follows:

- $80 \%$ of the subjects under investigation are high scores, which indicates that they have a great intellectual and cognitive potential and make a good impression, being reliable, fluent in speech, social efficiency, emotionally stable, mature, clear thinking, realistic, optimistic, responsible, well organized and ambitious.

- This percent of $80 \%$ of the subjects also are focused on achieving goals and values, have initiative and predictions, are valuable and effective leaders, are able to get cooperation from others to complete activities and to advise other team members. - Subjects with low scores are persons who lack selfconfidence, with many errors of expression, emotionally unstable, moody, peevish and anxious. These individuals tend to be dissatisfied, rebellious, defensive, immature, apathetic, irresponsible, and inconsistent in pursuing long-term objectives. In terms of reaction to change, it is worth noting that become anxious or insecure, tend to retreat in the face of adverse situations problematic. Some personality characteristics of the latter can be reconstructed by the institutionalized socialization achieved.

- Correlating the results obtained on these scales with sex of subjects, it was concluded that both boys and girls demonstrate qualities and skills that enable them to perform with the same effective leadership in the teams they belong.

Analysis of scores on each investigated dimension show a distribution over average of the possibilities for their subjects to join the work team (Table 1).

\begin{tabular}{|c|c|c|c|c|c|c|c|c|c|c|}
\hline & S1 & S2 & S3 & S4 & S5 & S6 & S7 & S8 & S9 & $\mathrm{S} 10$ \\
\hline Aservity & 2.6 & 3,5 & 3.4 & 3.2 & 4.0 & 3.6 & 4.0 & 3.6 & 4.2 & 4.3 \\
\hline $\begin{array}{r}\text { Analyze of the } \\
\text { missions }\end{array}$ & 4.3 & 3 & 3.0 & 3.8 & 4.0 & 4.0 & 3.3 & 3.8 & 4.6 & 4.8 \\
\hline Comunicate & 3.5 & 3.5 & 3.3 & 3.4 & 3.5 & 3.6 & 3.2 & 3.1 & 3.2 & 3.6 \\
\hline $\begin{array}{r}\text { Decision } \\
\text { taken }\end{array}$ & 4.4 & 4.0 & 2.8 & 3,4 & 3.4 & 2.8 & 3.2 & 3.4 & 3.7 & 3.7 \\
\hline Adaptability & 3.7 & 4.0 & 3.7 & 3.5 & 3.5 & 4.3 & 4.5 & 3.7 & 4.0 & 3.2 \\
\hline Leadership & 4.0 & 3.8 & 4.2 & 3.6 & 4.2 & 4.3 & 3.7 & 4.6 & 4.3 & 4.5 \\
\hline
\end{tabular}

Tab. 1. Analysis of scores on each subjects and investigated dimension

\section{CONCLUSION}

Theme undertaken by the issues the paper has, as follows from the theory and institutional practice, a particular importance, given the immediate implications in the functioning of social organizations, regardless of the social field in which they exists. From the theoretical point of view every social entity concerned, leader and team, has seized and shaped enough issues, despite their concerns to clarify ubiquitous. The separate approach can identify useful and relevant issues, but really efficient solutions can only come from a comprehensive approach to social reality.

The team is a complex social organization that characterizes the mechanism of processes reveal sometimes contradictory, always complicated. The purpose of the formation, operation and support team and state management cohesion or conflict within the team, represents aspects which under investigation process became challenges. Clearly the issue of leadership, leadership by practicing it has no way to not attract interest, because on the one hand it has a direct impact on team performance and, on the other hand, is still coveted goal of the first stages of its social becoming.

Customizations on various issues are useful and necessary situational contexts, from both theoretical perspective and experimental perspective.

Interpretation of data and correlations made between the results obtained lead us to validate the hypothesis formulated at the beginning of the study: the high level of leadership potential is compatible with the requirement of teamwork skills training. Compatibility of the two goals is a requirement of doctrinal nature, to which are devoted significant resources of time.

Interpretation of data and correlations made between the results obtained lead us to validate the hypothesis formulated at the beginning of the study: the high level of leadership potential is compatible with the requirement of teamwork skills training. Compatibility of the two goals is a requirement doctrinal nature, to which significant resources are devoted to time.

Theme issues undertaken in the paper has, as follows from the theory and institutional practice, a particular importance, given the immediate implications in the functioning of social organizations. From the theoretical point of view, every social entity concerned, team and leader, present no enough seized and shaped issues, despite their concerns to clarify them. The separate approach allows identifying the useful and relevant issues, but the really efficient solutions can come only from a comprehensive approach to social reality.

It should be noted that not all people exhibit these personality characteristics that facilitate their formation as leaders and their optimal integration in teams. It follows that for a governor is very important to know his subordinates so that, since the design of network statuses and roles specialization specific team, to ensure the interpersonal compatibility that enhances the cohesion and synergy of the team.

\section{REFERENCES}

Brannick, M., Salas, E., Prince, C.(2006), Team performance assessment and measurement: Theory, Methods, and Applications, Mahwah Publisher, New Jersey

Duda-Daianu D.C., Izvercianu M., Staicu F.(2007), Aspects regarding the importance of human resources for economic growth, Proceedings of the $5^{\text {th }}$ International Conference Management of Technological Changes, 22-25 September 2007, Alexandroupolis, Greece, ISBN 978-960-89832-8-1, Performantica Publisher, Iasi, p.179-184

Kets de Vries, M.(2003), Leadership - the art and the ability to lead, CODECS Publisher, ISBN Codecs 12, Bucharest

Maxwell, J.(2009), Teamworks 100: What Everu Leader Needs to Know, Thomas Nelson Publisher, ISBN 978-1400208025-4, Nashville, Tennessee

Nicolescu, O.(2004), The managers and human resources management, Economica Publisher, ISBN 978-973-841545-4, Bucharest

West, M., A.(2005), The work in team, Polirom Publisher, ISBN 978-3-486-58346-5, Bucharest

Zlate, M.(2004), Leadership and management, Polirom Publisher, ISBN 973-681-616-8, Iasi 